Original Article

\title{
DEVELOPMENT OF GASTRO RETENTIVE FLOATING M ATRIX TABLETS OF DILTIAZEM HYDROCHLORIDE
}

\author{
R. Narayana Charyulu ${ }^{1}$, Amit B. Patil, Lakshmi Deepika C.H, Prabhakar Prabhu, Shastry C.S \\ ${ }^{1}$ Department of Pharmaceutics, Nitte Gulabi Shetty M emorial Institute of Pharmaceutical Sciences, \\ Paneer, Deralakatte, Mangalore - 575018
}

Correspondence:

\section{R. Narayana Charyulu}

Vice Principal \& Head, Department of Pharmaceutics, NGSM Institute of Pharmaceutical Sciences, Paneer, Deralakatte, M angalore - 575018

E-mail : charyulun@yahoo.co.in

\begin{abstract}
:
The objective of the present investigation was to formulate and evaluate hydrodynamically balanced floating matrix controlled drug delivery system of diltiazem hydrochloride. Floating matrix tablets are associated with advantages of increased bioavailability and minimizing the dosing frequency. Diltiazem hydrochloride is a calcium channel blocker, an anti-hypertensive and anti-anginal drug, which undergoes extensive firstpass metabolism and display poor bioavailability. It has an elimination half-life of 3 to $4.5 \mathrm{~h}$ and an absorption zone from the upper intestinal tract. Gastric floating of diltiazem hydrochloride tablets results from effervescence produced by the reaction between sodium bicarbonate and hydrochloric acid in stomach. Seven formulations of floating tablets were prepared using direct compression technique with low viscosity polymer such as HPMC K100LV, high viscosity polymers such as HPMC K4M, K15M, and carbopol in different ratios. The evaluation results revealed that all formulations comply with the specification of official pharmacopoeias and/or standard reference with respect to general appearance, content uniformity, hardness, friability and buoyancy. Accelerated stability studies carried out at different temperatures, $27 \pm 2{ }^{\circ} \mathrm{C}$, $40 \pm 2{ }^{\circ} \mathrm{C}$ and $7 \pm 2{ }^{\circ} \mathrm{C}$ did show no changes in physicochemical properties at the end of 8 weeks indicating all the formulations are stable. Out of all the formulation developed, formulation $\mathrm{F}_{6}$ containing equal ratio of HPM CK4M and K100LV showed optimum floating time and in vitro drug release of $82.19 \%$ at the end of $8 \mathrm{~h}$. Thus it is summarized; high viscosity grade polymer HPM CK4M, low viscosity grade polymer HPM CK100LV and carbopol can be successfully used in formulation of sustained release gastro retentive floating drug delivery system.
\end{abstract}

Keywords : Gastro retentive floating matrix tablets, controlled drug release, diltiazem hydrochloride, low density polymers, high density polymers

\section{Introduction}

The oral drug delivery is by far the most preferable route of drug delivery system, due to ease of administration, patient compliance, and flexibility in formulation etc. It is evident from the recent scientific and patent literature that an increased interest in novel dosage form that are retained in stomach for a prolonged period of time exists today in academic and industrial research groups ${ }^{1}$. One of the most feasible approaches for achieving a prolonged and predictable drug delivery in the GI tract is to control the gastric residence time, i.e. gastro retentive dosage form. Effective oral drug delivery may depend upon the factor such as gastric emptying process, gastro intestinal transit time of dosage form, drug release from the dosage form and site of absorption of drug. Most of the oral dosage forms possess several physiological limitations such as variable gastrointestinal transit, because of variable gastric emptying leading to nonuniform absorption profiles, incomplete drug release and shorter residence time of the dosage form in the stomach. The gastric emptying of dosage forms in humans is affected by several factors because of which wide inter- and intra-subject variations are observed. Since many drugs are well absorbed in the upper part of the gastrointestinal tract, such high variability may lead to non-uniform absorption and makes the bioavailability 
unpredictable $e^{1,2,3}$. Among the various gastro retentive systems, gastric floating drug delivery systems (GFDDS) offer numerous advantages over the gastric retentive systems. These systems have a density lower than the gastric fluids and thus remain buoyant in the stomach without affecting the gastric emptying rate for a prolonged period of time. While the system is floating on the gastric contents, the drug is released slowly at a desired rate from the stomach ${ }^{4,5,6}$. Cardiovascular diseases are one of the life threatening diseases of the world. Angina pectoris, hypertension and cardiac failure are the commonest diseases and require constant monitoring ${ }^{7,8}$. Calcium channel blockers are emerging as very important group of the management of angina pectoris and hypertension. Diltiazem hydrochloride is a calcium channel blocker. It is widely prescribed for the treatment of hypertension and angina. Diltiazem hydrochloride undergoes an extensive biotransformation results in bioavailability of $30 \%$ to $40 \%$ only. It has an elimination half-life of 3 to $4.5 \mathrm{~h}$ and has an absorption zone from the upper intestinal tract. Efficacy of the administered dose may get reduced due to incomplete drug release from the device above the absorption zone. The dosage is $30 \mathrm{mg}, 4$ times a day and increased as necessary up to $360 \mathrm{mg} /$ day in divided doses $^{9,10}$. Due to short half-life diltiazem hydrochloride require frequent administration. These disadvantages can overcome by developing a floating dosage form to be remained buoyant in the stomach. The gastroretentive drug delivery systems can be retained in the stomach and assist in improving the oral sustained delivery of drugs that have an absorption window in a particular region of the gastrointestinal tract. These systems help in continuously releasing the drug before it reaches the absorption window and thus ensuring optimal bioavailability.

\section{Materials and Methods}

Diltiazem Hydrochloride was obtained as a gift by Cadila
Zydus, Ahmedabad and HPM C K4M , HPM CK15M , HPM C KIOOLV and Carbopol 934P was gifted by Wockhardt, Aurangabad.

\section{Formulation of floating matrix tablets of Diltiazem Hydrochloride by direct Compression}

The powder mixture containing drug, polymers and other excipients were weighed as per required quantity and thoroughly blended in a mortar and pestle and then passed through sieve No. 100. An Appropriate amount of the mixture was weighed and fed into the die of Minipress II using $8 \mathrm{~mm}$ punch to get tablets of average weight of $250 \mathrm{mg}^{11,12,13,14}$. The formula for the different batches is given in the Table 1 .

\section{Evaluation of Floating Tablets of Diltiazem Hydrochloride}

\section{Pre-Compression Evaluation Parameters}

\section{(a) Angle of Repose}

The angle of repose of powder blend was determined by the funnel method. Accurately weighed powder blend was taken in the funnel. The height of the funnel was adjusted in such a way the tip of the funnel just touched the apex of the powder blend. The powder blend was allowed to flow through the funnel freely on to the surface. The diameter of the powder cone was measured and angle of repose was calculated using following formula ${ }^{15,16}$.

$$
\begin{aligned}
& \operatorname{Tan} \theta=h / \mathbf{r} \\
& \boldsymbol{\theta}=\tan ^{-1} \mathbf{h} / \mathbf{r}
\end{aligned}
$$

Where, $\theta=$ angle of repose, $h=$ height, $r=$ radius.

\section{(b) Bulk Density}

The bulk density of a powder is dependent on particle packing and changes as the powder consolidates. A consolidated powder is likely to have a greater arch strength than a less consolidated one and therefore more resistant to powder flow. The ease with which a 
powder consolidates can be used as an indirect method of quantifying powder. Apparent bulk density $(\mathrm{g} / \mathrm{ml})$ was determined by pouring preserved bulk powder into a graduated cylinder via a large funnel and measuring the volume and weight ${ }^{15,16}$. Bulk density can then be calculated by the following formula.

\section{Bulk density $=\mathbf{W} /$ Vo}

Where, $\mathrm{W}=\mathrm{wt}$. of powder, $\mathrm{V}_{0}=$ initial volume.

\section{(c) Tapped Density}

A quantity of $2 \mathrm{gm}$ of powder blend from each formula, previously shaken to break any agglomerates formed, was introduced in to $10 \mathrm{ml}$ measuring cylinder. After that the initial volume was noted and the cylinder was allowed to fall under its own weight on to a hard surface from the height of $2.5 \mathrm{~cm}$ at second intervals. Tapping was continued until no further change in volume was noted ${ }^{15,16}$. Tapered density was calculated using the following equations.

\section{Tapped density $=\mathbf{W} / \mathbf{V}_{\mathrm{f}}$}

Where, $W=$ wt. of powder, $V_{f}=$ final volume.

\section{(d) Compressibility Index (Carr's Consolidation Index)}

The Compressibility indexis measure of the propensity of a powder to be compressed. As such, they are measures of the relative importance of interparticulate interactions. In a free-flowing powder, such interactions are generally less significant, and the bulk and tapped densities will be closer in value. For poorer flowing materials, there are frequently greater interparticle interactions, and a greater difference between the bulk and tapped densities will be observed. These differences are reflected in the Compressibility Index ${ }^{15,16}$. The compressibility index is calculated using measured values for bulk density $\left(D_{b}\right)$ and tapped density $\left(D_{t}\right)$ as follows:

\section{Compressibility index $=$ Dt $-D_{b} / D_{t} \times 100$}

Where $D_{b}=$ Bulk density, $D_{t}=$ Tapped density

\section{Post-Compression Parameters}

\section{(a) Tablet Dimensions}

Thickness and diameter of five tablets randomly selected were measured using vernier calipers. The Pharmacopoeia states that the extent of deviation in a batch of tablet should not exceed the limit of $\pm 5 \%$ of their determined standard values ${ }^{16,17}$.

\section{(b) Hardness Test}

The crushing strength $\mathrm{kg} / \mathrm{cm}^{2}$ of prepared tablets was determined for tablets of each batch by M onsanto tablet hardness tester. Hardness indicates the ability of a tablet to withstand mechanical shocks while handling ${ }^{16,17}$.

\section{(c) Friability Test}

The friability of tablets was determined using Roche friabilator. It is expressed in percentage (\%). Ten tablets randomly selected were initially weighed $\left(\mathrm{W}_{0}\right.$ initial) and transferred into friabilator. The friabilator was operated at $25 \mathrm{rpm}$ for 4 minutes or run up to 100 revolutions. The tablets were weighed again (W final) ${ }^{16,17}$. The percentage friability (\%F) was then calculated by

$$
\% F=\left(1-W / W_{0}\right) \times 100
$$

Where, $\mathrm{W}_{0}=$ weight of tablet before test, $W=$ weight of tablet after test.

\section{(d) Weight Variation Test}

Twenty tablets were selected randomly from each batch and weighed individually using electronic balance (Ohause) to check for weight variation ${ }^{16,17}$. Pharmaco poeial parameters are displayed in Table 2.

\section{(e) Drug Content Estimation}

Ten tablets were randomly selected and powdered. A quantity of powder equivalent to $60 \mathrm{mg}$ of diltiazem hydrochloride was accurately weighed and transferred into a $100 \mathrm{ml}$ volumetric flask and dissolved in $0.1 \mathrm{~N} \mathrm{HCl}$ and the volume was made with $0.1 \mathrm{~N} \mathrm{HCl}(\mathrm{pH} \mathrm{1.2).} \mathrm{The}$ flask was shaken on a flask shaker for $24 \mathrm{~h}$ and was kept for $12 \mathrm{~h}$ for the sedimentation of undissolved materials. 
The solution was filtered through Whattman filter paper. $1 \mathrm{ml}$ of the above solution was transferred to a $100 \mathrm{ml}$ volumetric flask and diluted to $100 \mathrm{ml}$ with $0.1 \mathrm{~N} \mathrm{HCl}$ and the absorbance was measured at $236 \mathrm{~nm}$ using UV / visible spectrophotometer (Shimadzu UV - 1600/1700). The percentage of diltiazem hydrochloride was determined using calibration curve $e^{9,10}$.

\section{(f) In Vitro Buoyancy Test}

The prepared tablets were subjected to in vitro buoyancy test by placing them in $250 \mathrm{ml}$ beaker containing $200 \mathrm{ml}$ $0.1 \mathrm{~N} \mathrm{HCl}\left(\mathrm{pH} 1.2\right.$, temp. $\left.37 \pm 0.5^{\circ} \mathrm{C}\right)$. The time between introduction of the dosage form and its buoyancy in the medium and the floating durations of tablets was calculated for the determination of lag time and total buoyancy time by visual observation. The Time taken for dosage form to emerge on surface of medium called Floating Lag Time (FLT) or Buoyancy Lag Time (BLT) and total duration of time by which dosage form remain buoyant is called Total Floating Time (TFT) ${ }^{9,10,11,13}$.

\section{(g) In Vitro Dissolution Studies}

The dissolution study was carried out using USP II (paddle method) apparatus in $900 \mathrm{ml}$ of $0.1 \mathrm{~N} \mathrm{HCl}$ (pH 1.2) for 12 $\mathrm{h}$. The temperature of the dissolution medium was kept at $37 \pm 0.5 \stackrel{\circ}{ } \mathrm{C}$ and the paddle was set at $100 \mathrm{rpm} .10 \mathrm{ml}$ of sample solution was withdrawn at specified interval of time and filtered through Whattman filter paper. The sample was replaced with fresh dissolution medium. The sample diluted to a suitable concentration with $0.1 \mathrm{~N}$ $\mathrm{HCL}$. The absorbance of the withdrawn samples was measured at $\lambda_{\max } 236 \mathrm{~nm}$ using a Shimadzu UV$1600 / 1700$ series spectrophotometer ${ }^{11,13,20}$.

\section{(h) Stability Studies}

The stability studies of all the formulations were studied at different temperatures using the reported standard procedure. The tablets were wrapped in aluminum foil and placed in Petri dishes. These containers were stored at ambient humid conditions, at room temperature ( $27 \pm$ $\left.2{ }^{\circ} \mathrm{C}\right)$, oven temperature $\left(40 \pm 2{ }^{\circ} \mathrm{C}\right)$ and in refrigeration temperature $\left(7 \pm 2{ }^{\circ} \mathrm{C}\right)$ for a period of 8 weeks. The samples were analyzed for physical changes such as color, texture, in vitro floating time ${ }^{21}$.

\section{Results and Discussion}

\section{Pre-Compression Evaluation Parameters}

The angle of repose for all the powders lies below $25^{\circ}$, indicating excellent flow properties. The Compressibility Index (Carr's Consolidation Index) is determined from the values of bulk density and tapered density. The values from the Table 3 reveals that HPM C K4M, K15M and K100LV are having good flow properties as their values are in range of 12 to 16 , where as the values between 18 to 21 of carbopol 934P and diltiazem hydrochloride indicates fair flow properties. The overall values obtained from the study of Pre-Compression evaluation parameters indicates that the powder blend have the required flow property to undergo tablet formulation by direct compression technique.

\section{Post-Compression Parameters}

\section{Tablet Dimensions}

Thickness and diameter of the seven formulations did not exceed the limit of $\pm 5 \%$ of the determined standard value; hence all the formulations comply with the proposed limits of pharmacopoeia. The values are shown in the tablets 4.

\section{Hardness Test}

The measured hardness of tablets of each batch ranged between 6.5 to $7.3 \mathrm{~kg} / \mathrm{cm}^{2}$ as reported in Table 4. This ensures good handling characteristics of all batches.

\section{Friability Test}

The $\%$ friability was found to be in the range $0.52 \%$ to $0.80 \%$ ensuring that the tablets are mechanically stable. The values of friability test are tabulated in Table 4.

\section{Weight Variation Test}


All the formulated tablets comply with the weight variation limits of the Indian Pharmacopoeia as the values are in the range of $1.5 \%$ to $3 \%$ as displayed in Table 4.

\section{Drug Content Estimation}

The percentage of drug content for $F_{1}$ to $F_{7}$ was found to be in the range of $97.82 \%$ to $99.41 \%$, as tabulated in Table 4 , of diltiazem hydrochloride, it complies with official specifications.

\section{In Vitro Buoyancy Test}

In Vitro buoyancy test was performed on all the batches $\left(F_{1}\right.$ to $\left.F_{7}\right)$. On immersion in 0.1N HCL solution pH (1.2) at $37^{\circ} \mathrm{C}$, the tablets floated, and remained buoyant without disintegration. Table 5 shows the results of in vitro buoyancy study from the results it can be concluded that the batch containing high viscosity grade HPM C K4M or HPM C K15M polymer and carbopol i.e. formulations $F_{1}$, $F_{4}$ and $F_{6}$ showed good buoyancy, total floating time of more than $8 \mathrm{~h}$, whereas formulation $\mathrm{F}_{3}$ containing low viscosity grade polymer HPM C K100LV displayed floating time of less than $5 \mathrm{~h}$ and the formulations $\mathrm{F}_{2}, \mathrm{~F}_{5}$ and $\mathrm{F}_{7}$ floated till $7 \mathrm{~h}$.

\section{In Vitro Dissolution Studies}

In vitro dissolution studies showed highest drug release of $82.19 \%$ from the formulation $F_{6}$ followed by $F_{5}, F_{2}, F_{7}, F_{3}$, $F_{4}$ and $F_{1} . F_{6}$ formulation contains equal ratio of HPMC $\mathrm{K}_{4} \mathrm{M}$ and K100LV. Fig 1 shows the drug release pattern of all the formulations.

\section{Discussion}

The overall values obtained from the study of PreCompression evaluation parameters indicates that the powder characteristics of diltiazem hydrochloride, HPM C K100LV, K4M, K15M, and carbopol 934P, with the selected excipients has the optimum flow properties necessary to be blended together and undergo tablet formulation by direct compression technique.
The Post-Compression evaluation parameters of 7 formulation, reveals that, all the prepared formulation comply with the official standards mentioned in pharmacopoeia for tablet dimension, hardness test, friability test, weight variation test and drug content estimation. The in vitro buoyancy studies showed optimum floating time of more than $8 \mathrm{~h}$ for the formulation $F_{1}, F_{4}$ and $F_{6}$ when compared to other formulations. The results reviles that the formulation $F_{6}$ containing equal ratio of HPM C K4M and K100LV is the best formulations as the extent of in vitro drug release was found to be $82.19 \%$ in $8 \mathrm{~h}$ and followed zero order drug release kinetics. The drug release profile of $F_{6}$ formulation appear to be biphasic; as the first phase is characterized by initial burst effect followed by controlled slow release in second phase. This peculiar behavior may be explained as, when the tablet comes in contact with dissolution medium, the low viscosity grade polymer HPMC K100LV result in faster and greater amount of gel formation initially resulting in immediate drug release from the pores formed during gelling. The drug release is then controlled by the high viscosity grade polymer HPMC K4M which also contributes to higher floating time i.e. more than $8 \mathrm{~h}$. when high molecular weight carbopol 934P, a cross linking polymer, comes in contact with water it swells and hold water inside the microgel network. This property helps in partially retarding the drug release which further enhances the control release property of the formulated gastro retentive floating drug delivery system. The tablets remained intact during the dissolution period. The accelerated stability studies performed at room temperature $\left(27 \pm 2^{\circ} \mathrm{C}\right)$, oven temperature $\left(40 \pm 2^{\circ} \mathrm{C}\right)$ and in refrigeration temperature $\left(7 \pm 2^{\circ} \mathrm{C}\right)$ did show no changes in physicochemical properties at the end of 8 weeks indicating all the formulations are stable.

\section{Conclusion}

The pre-compression evaluation parameters concludes 
that it is feasible to formulate diltiazem hydrochloride gastro retentive floating matrix tablet by direct compression technique, using low viscosity polymer such as HPM C K100LV, high viscosity polymers such as HPM CK4M , K15M , and carbopol 934P in different ratios.

The post-compression evaluation parameters reveals prepared Floating matrix tablets of diltiazem hydrochloride possessed optimum tensile strength, hardness and friability. This indicates good mechanical strength for handling and transportation of the prepared tablet formulation. It was observed that the floating matrix tablet formulated with equal ratio of high viscosity grade polymer HPMC K4M and low viscosity grade polymer HPMC K100LV with carbopol 934P resulted not only in higher in vitro buoyancy time but also showed optimum controlled in vitro drug release profile that followed zero order kinetics. The fact this tablet formulation also remained intact during the dissolution period, is one of the encouraging observations. The Accelerated stability studies carried out at different temperatures did show no changes in physicochemical properties at the end of 8 weeks concluding all the formulations are stable.

The specific objective of formulation and evaluation of the gastro retentive floating matrix tablets of diltiazem hydrochloride for reducing the dose frequency and control release of the diltiazem hydrochloride is optimally achieved. There is a need to extend the formulations reported in this research article for commercial exploitation.

Table 1. Formulation composition of floating matrix tablets of diltiazem hydrochloride

\begin{tabular}{|l|l|l|l|l|l|l|l|}
\hline Ingredients & $\mathbf{F}_{\mathbf{1}}$ & $\mathbf{F}_{\mathbf{2}}$ & $\mathbf{F}_{\mathbf{3}}$ & $\mathbf{F}_{\mathbf{4}}$ & $\mathbf{F}_{\mathbf{5}}$ & $\mathbf{F}_{\mathbf{6}}$ & $\mathbf{F}_{\mathbf{7}}$ \\
\hline & $\mathbf{( m g )}$ & $\mathbf{( \mathbf { m g } )}$ & $\mathbf{( m g )}$ & $\mathbf{( \mathbf { m g } )}$ & $\mathbf{( m g )}$ & $\mathbf{( \mathbf { m g } )}$ & $\mathbf{( \mathbf { m g } )}$ \\
\hline Diltiazem Hydrochloride & 60 & 60 & 60 & 60 & 60 & 60 & 60 \\
\hline HPMC K4M & 75 & - & - & 50 & - & 50 & 37.5 \\
\hline HPMC K15M & - & 75 & - & 50 & 50 & - & 37.5 \\
\hline HPMC KLOOLV & - & - & 75 & - & 50 & 50 & 37.5 \\
\hline Carbopol 934P & 75 & 75 & 75 & 50 & 50 & 50 & 50 \\
\hline Sodium bicarbonate & $\mathbf{5 0}$ & 50 & 50 & 50 & 50 & 50 & 50 \\
\hline Lactose & 29.6 & 29.6 & 29.6 & 29.6 & 29.6 & 29.6 & 29.6 \\
\hline Magnesium stearate & 5.2 & 5.2 & 5.2 & 5.2 & 5.2 & 5.2 & 5.2 \\
\hline Talc & 5.2 & 5.2 & 5.2 & 5.2 & 5.2 & 5.2 & 5.2 \\
\hline
\end{tabular}

, Each tablet contains uniform weight of $250 \mathrm{mg}$.

\section{Table 2. IP standards of percentage of weight variation}

\begin{tabular}{|l|l|}
\hline \multicolumn{2}{|c|}{ Percentage deviation allowed under weight variation test. } \\
\hline \multicolumn{1}{|c|}{ Average weight of tablet } & \multicolumn{1}{c|}{ Percentage deviation } \\
\hline $80 \mathrm{mg}$ or less 10 & 10 \\
\hline M ore than $60 \mathrm{mg}$ but less than $250 \mathrm{mg} 7.5$ & 7.5 \\
\hline $250 \mathrm{mg}$ or more 5 & 5 \\
\hline
\end{tabular}

I Since, the average weight of the tablets is $250 \mathrm{mg}$; the percentage deviation is taken as \pm 5 
Table 3. Pre-Compression evaluation parameters

\begin{tabular}{|l|l|l|l|l|l|}
\hline $\begin{array}{l}\text { Pre-Compression } \\
\text { evaluation } \\
\text { parameters }\end{array}$ & $\begin{array}{l}\text { HPMC } \\
\text { K4M }\end{array}$ & $\begin{array}{l}\text { HPMC } \\
\text { K15M }\end{array}$ & $\begin{array}{l}\text { HPMC } \\
\text { K100LV }\end{array}$ & $\begin{array}{l}\text { Carbopol } \\
934 \mathrm{P}\end{array}$ & $\begin{array}{l}\text { Diltiazem } \\
\text { hydrochloride }\end{array}$ \\
\hline Angle of Repose & 17.28 & 18.26 & 18.12 & 19.28 & 20.67 \\
\hline Bulk Density & 0.472 & 0.471 & 0.475 & 0.485 & 0.446 \\
\hline Tapped Density & 0.561 & 0.568 & 0.555 & 0.598 & 0.568 \\
\hline $\begin{array}{l}\text { Compressibility/ } \\
\text { Carr's Index }\end{array}$ & 15.86 & 17.077 & 14.414 & 18.896 & 21.478 \\
\hline
\end{tabular}

Table 4. Post-Compression parameters

\begin{tabular}{|l|l|l|l|l|l|l|}
\hline $\begin{array}{l}\text { Formulation } \\
\text { Code }\end{array}$ & $\begin{array}{l}\text { Tablet } \\
\text { thickness } \\
\pm \mathrm{SD}(\mathrm{mm})\end{array}$ & $\begin{array}{l}\text { Diameter } \\
(\mathrm{mm})\end{array}$ & $\begin{array}{l}\text { Hardness } \\
\pm \mathrm{SD} \mathrm{kg} / \mathrm{cm}^{2}\end{array}$ & $\begin{array}{l}\text { Friability } \\
(\%)\end{array}$ & $\begin{array}{l}\text { Weight } \\
\text { variation }\end{array}$ & $\begin{array}{l}\text { Drug } \\
\text { content (\%) } \\
\text { test (\%) }\end{array}$ \\
\hline $\mathrm{F}_{1}$ & $2.7 \pm 0.04$ & 8 & 6.5 & 0.25 & 2.29 & 99.41 \\
\hline $\mathrm{F}_{2}$ & $2.6 \pm 0.02$ & 8 & 7.2 & 0.64 & 1.84 & 99.00 \\
\hline $\mathrm{F}_{3}$ & $2.9 \pm 0.01$ & 8 & 6.9 & 0.80 & 2.37 & 97.82 \\
\hline $\mathrm{F}_{4}$ & $2.7 \pm 0.03$ & 8 & 6.7 & 0.55 & 2.19 & 98.28 \\
\hline $\mathrm{F}_{5}$ & $2.6 \pm 0.02$ & 8 & 6.8 & 0.72 & 2.71 & 99.25 \\
\hline $\mathrm{F}_{6}$ & $2.9 \pm 0.01$ & 8 & 7.3 & 0.55 & 2.04 & 98.51 \\
\hline $\mathrm{F}_{7}$ & $2.5 \pm 0.03$ & 8 & 7.1 & 0.60 & 2.90 & 98.82 \\
\hline
\end{tabular}

SD = Standard Devation

Table 5. In Vitro Buoyancy studies

\begin{tabular}{|c|c|c|}
\hline Formulation Code & Buoyancy Lag Time (sec) & Total Floatation Time (h) \\
\hline F1 & 100 & $>8$ \\
\hline F2 & 120 & $\sim 7$ \\
\hline F3 & 150 & $? 5$ \\
\hline F4 & 120 & $>8$ \\
\hline F5 & 125 & $\sim 7$ \\
\hline F6 & 132 & $>8$ \\
\hline F7 & 140 & $\sim 7$ \\
\hline
\end{tabular}

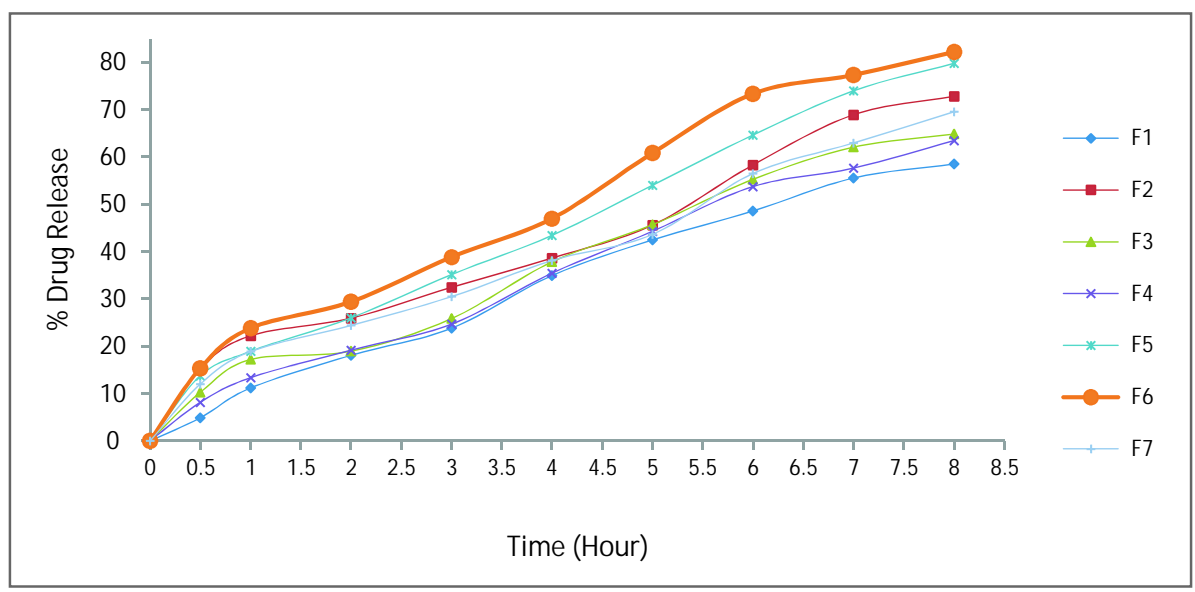

Fig 1. In-vitro dissolution profile of formulations $F_{1}$ to $F_{7}$ 


\section{References}

1. http://www.pharmainfo.net/reviews/floating-drug-delivery-system.

2. Vyas SP and Roop K Khar. Controlled drug delivery concepts and advances. 1st edn. 2002; pp.196-217, New Delhi.

3. Chien YW. Novel drug delivery systems. 2nd edn. (Marcel Dekker Inc), 1992; pp. 1-3, New Yorkand Basel.

4. Sanjay Garg and Shringi Sharma. Gastro retentive drug systems. Pharmatech 2003; pp. 160-166.

5. Shirwaikar AA, Kumar SMR, Jacob S, Rashi W and Ravi K. Recent developments in floating drug delivery systems for gastric retention of drugs. An overview. Indian Drugs Sep 2006; 43(9): 697-703.

6. Bardonnet PL, Faivre V, Pugh WJ, Piffaretti JC and Falson F. Gastro retentive dosage forms: Overview and special case of helico bacter pylori. J Control Release. 2006 Mar; 111: 1-2.

7. Torotora GJ, Grabowski SR. Principles of anatomy and physiology. 10th edn. 2002; pp. 78-90, John Willey and Sons, New York.

8. Wilson KRW, Waugh A. Anatomy and physiology in health and illness. 9th ed. 1996; pp. 342-345, Churchill Livingstone, London.

9. Indian Pharmacopoeia. M inistry of health and family welfare. Government of India. Vol 1. 1996; pp. 256-257, Controller of Publications, Delhi.

10. Kathleen Parfit. M artindale. The complete drug reference. 32nd ed. 1999; 778: pp. 854-857, The Pharmaceutical Press, London.

11. Shyamala Bhaskaran and Remiz M. Novel approach to zero order drug delivery via hydrogel for diltiazem hydrochloride. Indian J Pharm Sci 2002; 64(4): 357-361.

12. Shirwaikar AA and Srinatha A. Sustained release bilayered tablets of diltiazem hydrochloride using insoluble matrix system. Indian J Pharm Sci 2004; 66(4): 433-437.
13. Varma M , Singla AK and Dhawan S. Release of diltiazem hydrochloride from hydrophilic matrices of polyethylene oxide and carbopol. Dug Dev and Ind Pharm, Dec 2004; 30(5): 545-553.

14. Shoufeng Li, Senshang Lin, Bruce P Daggy, Haresh L M irchandani and Yie W Chien. Effect of hydroxypropyl methylcellulose and carbopol on the release and floating properties of gastric floating drug delivery system using factorial design. Int J Pharm 2003; $253(1,2): 13-22$.

15. Alfred Martin, Pilar Bustamante, Chun AHC. Physical pharmacy. 4th edn. 2001; pp. 446-448, B. I. Publications Pvt. Ltd, Lippincott Williams and Wilkins.

16. Lachmann L, Liebermann HA, KanigJL. The theory and practice of industrial pharmacy. 3rd edn. 1990; pp 253-296, Varghese publishing house, London.

17. Robinson JR and Lee TW. Controlled release drug delivery system. Remington. The science and Practice of Pharmacy. 20th ed. 2001; pp. 903904, Lippincott Williams and Wilkins, Philadelphia.

18. Brijesh S Dave, Avani F Amin and Madhabhai M Patel. Formulation and invitro evaluation of Gastro retentive drug delivery system of ranitidine hydrochloride. AAPSPharm Sci Tech 2004; 5(2): 34.

19. Mahesh Chavanpatil, Paras Jain, Sachin Chaudhari, Rajesh Shear and Pradeep vavia. Development of sustained release gastro retentive drug delivery system of ofloxacin: In vitro and in vivo evaluation. Int J Pharm 2005; 304 (1, 2): 178-184.

20. Gohel MC, Mehta PR, Dave PK and Bariya NH. More relevant dissolution method for evaluation of FDDS. Dissolution Technologies. Int J Pharm 2005; 22-25.

21. The European agency for the evaluation of medicinal products. Human's medicines evaluation unit. ICH Guidelines: ICH Topic QIA, note for guidance on Stability Testing of New Drug Substances (CPM P/ ICH/ 380/95): 1-14. 